\title{
Longitudinal Trends in Produce Purchasing \\ Behavior: A Descriptive Study of Transaction Level Data from Loyalty Card Households
}

Isabel Diana Fernandez ( $\nabla$ diana_fernandez@urmc.rochester.edu )

University of Rochester School of Medicine and Dentistry https://orcid.org/0000-0003-4497-0802

Brent A. Johnson

University of Rochester School of Medicine and Dentistry

Nellie Wixom

University of Rochester School of Nursing

Amber Kautz

University of Rochester School of Medicine and Dentistry

Joanne Janciuras

University of Rochester School of Medicine and Dentistry

Steve Prevost

Wegmans Food Markets

Jiebo Luo

University of Rochester Hajim School of Engineering and Applied Sciences

Rajeev S Ramchandran

University of Rochester School of Medicine and Dentistry

\section{Research Article}

Keywords: Food purchases, Produce Purchases, Loyalty card, Grocery Stores, Diet, Diet monitoring, Purchasing behavior

Posted Date: March 7th, 2022

DOI: https://doi.org/10.21203/rs.3.rs-1348304/v1

License: (c) (i) This work is licensed under a Creative Commons Attribution 4.0 International License.

Read Full License 
3 Level Data from Loyalty Card Households

4

5 Isabel Diana Fernandez, MD, MPH, PhD*

6 Department of Public Health Sciences, University of Rochester School of Medicine and

7 Dentistry, Rochester, NY, USA

8 email: diana_fernandez@urmc.rochester.edu

9 Brent A. Johnson, $\mathrm{PhD}$

10 Dept of Biostatistics and Computational Biology, University of Rochester School of Medicine

11 and Dentistry, Rochester, NY, USA

12 Nellie Wixom, BS, RD

13 School of Nursing, University of Rochester Medical Center, Rochester, NY, USA

14 Amber Kautz, MS, RDN, CDN.

15 Department of Public Health Sciences, University of Rochester School of Medicine and

16 Dentistry, Rochester, NY, USA

17 Joanne Janciuras

18 Dept of Biostatistics and Computational Biology, University of Rochester School of Medicine 19 and Dentistry, Rochester, NY, USA

20 Steve Prevost

21 Director, Customer Insights, Wegmans Food Markets, Rochester, NY 
22 Jiebo Luo, $\mathrm{PhD}$

23 Department of Computer Science, University of Rochester, Rochester, NY, USA

24 Rajeev S. Ramchandran, MD, MBA.

25 Department of Ophthalmology, University of Rochester School of Medicine and Dentistry,

26 Rochester, NY, USA

$27 *$ Corresponding author

28

29

30

31

32

33

34

35

36

37

38

39

40

41

42

43 


\section{Abstract}

45 Background: Household food purchases (HFP) are in the pathway between the community

46 food environment and the foods available in households for consumption. As such, HFP data

47 have emerged as alternatives to monitor population dietary trends over-time. In this paper, we

48 investigate the use of loyalty card datasets as unexplored sources of continuously collected HFP

49 data to describe temporal trends in household produce purchases.

50 Methods: We partnered with a grocery store chain to obtain a loyalty card database with grocery

51 transactions by household from January 2016-October 2018. We included households in an

52 urban county with complete observations for head of household age group, household income

53 group, and family size. Data were summarized as weighted averages (95\% CI) of percent

54 produce purchased out of all foods purchased by household per month. We modeled seasonal

55 and linear trends in the proportion of produce purchases by age group and income while

56 accounting for repeated observations per household using generalized estimating equations.

57 Results: There are 290,098 households in the database ( $88 \%$ of all county households). At

58 baseline, the smallest and largest percent produce purchases are observed among the youngest

59 and lowest income $(12.2 \%$, CI 11.1; 13.3) and the oldest and highest income households (19.3,

60 CI 18.9; 19.6); respectively. The seasonal variations are consistent in all age and income groups

61 with an April-June peak gradually descending until December. However, the average linear

62 change in percent produce purchased per household per year varies by age and income being the

63 steepest among the youngest households at each income level (from 1.42\%, CI 0.98;1.8 to

$640.69 \%$, CI 0.42;0.95) while the oldest households experience almost no annual change. 
65 Conclusions: We explored the potential of a collaboration with a food retailer to use

66 continuously collected loyalty card data for public health nutrition purposes. Our findings

67 suggest a trend towards a healthier pattern in long-term food purchases and household food

68 availability among the youngest households that may lessen the population chronic disease

69 burden if sustained. Understanding the foods available for consumption within households

70 allows public health advocates to develop and evaluate policies and programs promoting foods

71 and nutrients along the life course.

72

73 Key Words: Food purchases, Produce Purchases, Loyalty card, Grocery Stores, Diet, Diet

74 monitoring, Purchasing behavior.

75 Trial registration: Not applicable.

76

77

78

79

80

81

82

83

84

85 


\section{Background}

87 Diet-related non-communicable diseases (DRNCD) are the leading cause of morbidity and mortality globally and in the United States. Globally, $22 \%$ of all deaths and $15 \%$ of disability-

89 adjusted life-years (DALYs) were attributed to dietary factors (1). In the US, where DRNCD

90 disproportionally affect older adults, racial/ethnic minorities and lower income groups, dietary

91 factors accounted for the largest number of deaths and were the third leading cause of DALYs

92 (2). Of concern, dietary risk factors have remained relatively unchanged in the past 10 years (3).

93 Combined nutrition public health policy and programs addressing all components of the food 94 system will contribute to the improvement of dietary intake eventually lessening the population 95 burden of DRNCD $(1,2)$.

97 Monitoring population diet quality to identify food and nutrient inadequacies is necessary to 98 develop and evaluate public health nutrition policies and programs. To date, self-reported 99 dietary intake assessments, such as 24-hour dietary recalls or food frequency questionnaires, are 100 the most frequently used tools for nutrition monitoring (4). These tools are resource intensive, 101 prone to measurement errors and social desirability bias, and some do not capture seasonal 102 variation of food intake (5) if assessing a few days at a time (e.g.; 24-hour diet recalls, food 103 records); making them impractical to monitor long-term dietary intake at the population level. 104 To circumvent the limitations of self-report, the search for biomarkers of dietary intake has 105 intensified, particularly using metabolomics (6). Despite considerable advancement in the field, 106 few biomarkers of specific nutrients and food groups are available and even fewer capture 107 average long term dietary intake (7). Together with the challenges in the collection and storage 
108 of biological samples, biomarkers of dietary intake are not yet suitable for population monitoring 109 (8).

111 Food purchase data have gained popularity as an alternative method to monitor population 112 dietary intake trends and to evaluate nutrition policies and programs $(9,10)$. Food purchase data 113 by households do not directly measure individual dietary intake but rather represents the foods 114 available to consume by household members. People make food choices in the context of the 115 food stream, the flow of foods from the national food supply through food processing (e.g.; 116 manufacturers) and the community food environment (e.g.; markets, grocery stores, schools), to

117 individual food intakes (11). Food purchasing behavior is then considered a mediator between 118 the community food environment, the food available to members of a household and individuals' 119 dietary intake $(12,13)$. The mediator role of food purchasing behavior is supported by evidence 120 of its relative concordance with individual nutrient intakes $(12,14,15)$ and of providing 121 reasonable estimates of overall diet quality when compared with self-report methods (12). Thus, 122 household food purchases data appears to be suitable for population monitoring and evaluation. 123 Thus far, data on food purchases have been obtained from commercially available household 124 food purchasing panels and have examined the quality of food purchases of nutritional assistance 125 programs (e.g.; WIC), and the nutrient compositions of purchased foods at the brand-level,(10) 126 associations between sociodemographic factors and household food and beverage purchases, the

127 effect of marketing (e.g.; coupons) and public health interventions (e.g.; food taxes). A recent 128 report, however, has identified the need to develop partnerships between nutrition researchers 129 and independent and chain food retailers willing to share loyalty card data to support healthy 130 eating and to advance policy and practice (16). 
132 In this paper, we report the results of loyalty card data analyses based on a partnership between a 133 regional supermarket chain in Western New York that accounts for $65 \%$ of total dollar food 134 expenditure in the county (private communication with the food retailer) and an academic health 135 center as a demonstration of these collaborations' potential to advance public health nutrition.

136 We chose to focus on household purchases of fresh fruits and vegetables because they are major 137 sources of dietary fibers, antioxidants, flavonoids and polyphenols and primary components of 138 the Healthy U.S.-, Vegetarian-, and Mediterranean-Styles Patterns recommended by the US dietary 139 guidelines for the prevention of chronic conditions across the life course (17). Fruit and 140 vegetable intake is inversely associated with cardiovascular disease morbidity and mortality, and 141 all-cause mortality (18-21). Some studies have reported a lower incidence of pancreatic and 142 gastric cancers, age-related macular degeneration, and type 2 diabetes (20-22) with increased 143 fruit and vegetable consumption, although others have found weak or inconsistent associations 144 with all cancers $(18,23)$ and diabetes (19). Despite this evidence, population intake of fruits and 145 vegetables, as reported in national nutrition surveys $(24,25)$, is consistently below the 146 recommendations $(17,26)$. It follows that these food groups are ideal targets of public health 147 nutrition programs and policies for the prevention of DRNCD. The objective of this paper is to 148 describe household fresh fruits and vegetables (hereafter produce) purchases as the interface 149 between the community food environment and individual eating behaviors and to examine 150 temporal and seasonal trends by demographic characteristics. 
153 We follow the guidelines of Strengthening the Reporting of Observational Studies in

154 Epidemiology extension for nutritional epidemiology (STROBE-nut) (27) (Supplemental Table

$155 \quad 1)$

156 This is a secondary data analysis of a grocery store loyalty card database with household food

157 transactions to describe seasonal and temporal trends in fresh produce purchases from January

1582016 to October 2018 (33 months). The data were obtained as part of a long term collaboration

159 between the authors and a regional grocery store chain in a Western NY county. The dataset

160 includes all purchases of food and non-food items of loyalty cardholders by household.

161 Purchases made by each household member with a loyalty card are merged into a unique

162 household identifier and each household visit to a store is identified by a unique transaction

163 number and date. Household information includes zip code, household income (nine categories:

$164 \quad 0-14,9 \mathrm{~K} ; 15-19.9 \mathrm{~K}, 20-29,9 \mathrm{~K} ; 30-39,9 \mathrm{~K} ; 40-49.9 \mathrm{~K}, 50-74,9 \mathrm{~K} ; 75-99,9 \mathrm{~K} ; 100-124.9 \mathrm{~K} ; \geq 125 \mathrm{~K})$,

165 age of head of household (six categories: 18-24.9, 25-34.9, 35- 44.9, 45-54.9, 55-74.9, 75-89),

166 household size ( 1 to $\geq 6$ ), and whether or not the household is a family (yes/no). No data on

167 gender, education, nor race/ethnicity were available. Purchase information includes the store

168 where the purchase was made, a short description of the item, brand name, department (e.g.;

169 dairy), category (e.g.; yogurt), and class (e.g.; Greek yogurt). All data are de-identified except

170 for the household 5-digit zip codes, which are updated from the National Change of Address data

171 from the United States Postal Service. Likewise, the company updates all demographic data

172 from households annually using commercial databases. We included households in zip codes for

173 one mostly urban county (17 stores) and excluded all non-food related departments (e.g.;

174 pharmacy) and households with a head of household $\geq 90$ years old ( $1.6 \%$ of households $)$ under

175 the assumption that their involvement in food shopping is minimal (28) and to comply with 
176 research review board standards of using de-identified data. Additionally, we manually checked

177 all food departments to eliminate non-food products (e.g.; candy making mold and supplies and

178 pet foods found in bulk food department, coupons); and foods and drinks not considered for

179 households every day consumption (produce party trays $\geq 1$ pound, cheese and cold cut party

180 trays of $\geq 2$ pounds, beer kegs).

181 Variables:

182 Produce was identified as all fresh raw produce categories in the loyalty card database selected

183 from the department 'produce' (excluding frozen, dried, canned, juice): summer fruit, berries,

184 grapes, store organic farm, seasonal/specialty, apples and pears, salad vegetables, citrus, tropical

185 fruit, bananas, melons, potatoes and onions, cooking vegetables, and salad leaf. To model

186 seasonal and annual trends we estimated the weighted average of the percent produce purchases

187 (fresh produce purchased/all foods purchased) per household across all households per month

188 (weight $=$ the number of foods purchased per household) for 33 months. In this way, we

189 controlled for the effect of family size in the amount of produce purchased (larger families, more

190 purchases). In these analyses, each unique food item purchased in a single transaction is

191 considered to be one unit, regardless of true quantity purchased; thus, percent produce purchased

192 represents the frequency rather than the quantity of foods purchased. Categories of age groups

193 from the original dataset were collapsed (18-24, 25-34, 35-54, 55-74, and 75-89 years old)

194 because exploratory analyses showed overlapping percentage produce purchases over time in the

195 35-44 and 45-54 age groups. A similar finding among income groups allowed for additional data

196 reduction from nine groups to six $(0-14,9 \mathrm{~K} ; 15-29,9 \mathrm{~K} ; 30-49,9 \mathrm{~K} ; 50-74,9 \mathrm{~K} ; 75-99,9 \mathrm{~K} ;>100 \mathrm{~K})$.

$197 \quad$ Statistical Analyses 
198 We describe the characteristics of loyalty card households by age of head of household,

199 household income, family (yes/no), and household size. To assess how representative the loyalty

200 card households were of the general population of the county, we compared the proportion of

201 households in each household income and age of head of household groups with county data

202 from 2017 American Community Survey (ACS) (29). Since the ACS does not include data on

203 age of head of households, we compared our data to the county population age groups. For

204 comparison with the available ACS household income groups, we collapsed groups 15-29.9K

205 and 30-49.9K into a 15-49.9K income group.

206

207 We modeled temporal trends in the proportion of percent fresh produce purchases over time

208 while accounting for repeated observations per household using generalized estimating equations

209 (30, 31). The basic statistical model used to describe purchasing trends is

210

Equation (1)

$$
\begin{gathered}
\operatorname{logit}\left\{P\left(Y_{i j}=y_{i j}\right)\right\}=\beta_{0}+\beta_{S} s\left(t_{i j}\right)+\beta_{L} t_{i j}+\beta_{X} X_{i}+\beta_{X L}\left(X_{i} \times t_{i j}\right) \\
\beta_{S} s\left(t_{i j}\right)=\beta_{S_{1}} \sin \left(\frac{2 \pi t_{i j}}{12}\right)+\beta_{S_{2}} \cos \left(\frac{2 \pi t_{i j}}{12}\right)
\end{gathered}
$$

212 where, $Y_{i j}$ is a binomial random variable representing the number of fresh produce items

213 purchased by the $i$ th household during the $j$ th month based on a total of $n_{i j}$ food items purchased

214 during the $j$ th month. The terms in the model include time $\left(t_{i j}\right)$ recorded as an integer from 1 to

$21533, X_{i}$ are demographic variables (age or income groups), and $X_{i} \times t_{i j}$ are covariate-by-time

216 interactions (age group $\mathrm{x}$ time; income group $\mathrm{x}$ time; age group $\mathrm{x}$ income group $\mathrm{x}$ time).

217 Importantly, seasonal trends of percent produce purchased $s\left(t_{i j}\right)$ are modeled as the sum of

218 sinusoidal and cosinusoidal terms as written in the second line of Equation (1). The unknown 
219 regression coefficients are $\beta_{0}, \beta_{S_{1}}, \beta_{S_{2}}, \beta_{L}, \beta_{X}, \beta_{X L}$ and estimated by the statistical procedure.

220 Thus, the percent fresh produce purchasing trends are modeled as the sum of seasonal

221 variations $\left(\beta_{S}\right)$ and linear trends $\left(\beta_{L}\right)$ over time, with the linear trends different by age and

222 income groups. We draw statistical inference using the robust empirical sandwich covariance

223 under a working independence correlation model. We use linear contrasts of coefficients in

224 models via Equation (1) that include the three-way time-by-age-by-income interaction to

225 estimate the age-by-income slopes over the 33-month period. After rescaling the coefficients,

226 the slopes are interpreted as the average linear change in percent produce purchased per

227 household per year over 33 months after controlling for seasonal variation. We depicted the

228 seasonal variations graphically by overlaying the fitted curve atop the data; in these figures (1

229 and 2), the data are summarized as weighted averages of percent produce purchased by

230 household across all households per month and a 95\% confidence interval, where weight is equal

231 to the number of foods purchased per household. We included a horizontal line in each graph

232 representing the grand mean of percent produce purchased by household as a reference. The

233 analysis of repeated binomial proportions has a rich history in the statistics literature and is an

234 appropriate tool for modeling the percent produce purchased in our sample. Because the

235 proportion is the ratio of number of produce items purchased divided by the total number of food

236 items purchased and re-computed on a monthly basis per household, the statistic controls

237 automatically for monthly fluctuations in number of food items purchased per household.

238 Furthermore, the precision of the proportion of produce items purchased increases as the number

239 of total food items purchased increases. Thus, households that purchase more food items are

240 weighted more heavily in the analysis. We analyzed data with complete observations. Models

241 were fit in SAS statistical software (SAS Version 9.4; SAS Institute, Cary, NC). The University 
242 of Rochester Human Subjects Review Board approved all study procedures and granted a waiver

243 of consent.

\section{RESULTS}

$\underline{\text { Descriptive Statistics }}$

247 There are 290,098 households who are loyalty cardholders in the county, of which $4 \%$ and $9 \%$ had 248 missing data on age of head of household and household income, respectively, and $15 \%$ had 249 missing data on family status (yes/no) and family size. Consequently, sample size totals in Tables 250 1-3 differ. Most of the head of households are in the 35-54 and 55-74 age groups (72\%) while less 251 than $3 \%$ are in the youngest age group (18-24). The largest income group among loyalty card 252 households $(28 \%)$ is $50-74.9 \mathrm{k}$, while $6 \%$ are in the lowest income bracket $(0-14.9 \mathrm{~K})$ (table 1$)$. 253 Half of the households identified themselves as a family, 81\% of them have 1-4 members (table 254 2). Loyalty card households constitute $88 \%$ of all county households in 2017 . The loyalty card 255 database has a smaller proportion of households in the lower income groups $(\leq \$ 49.900)$ than 256 county households, $35.5 \%$ vs $45.6 \%$, respectively, and older head of households ( $\geq$ aged 55) than 257 the county population, $47 \%$ vs. $37 \%$, respectively (table 3 ). 
Table 1. Characteristics of Loyalty Card Households by Age and Income groups. January 2016-October 2018

\section{Annual Household Income}

\begin{tabular}{|l|c|c|c|c|c|c|c|}
\hline $\begin{array}{c}\text { Age Head } \\
\text { of }\end{array}$ & $\mathbf{0 - 1 4 . 9 ~ K}$ & $\mathbf{1 5 - 2 9 . 9 K}$ & $\mathbf{3 0 - 4 9 . 9 K}$ & $\mathbf{5 0}-\mathbf{7 4 , 9 K}$ & $\mathbf{7 5 - 9 9 . 9 K}$ & $\mathbf{1 0 0 K}$ & All \\
Household & $\%(\mathrm{n})$ & $\%(\mathrm{n})$ & $\%(\mathrm{n})$ & $\%(\mathrm{n})$ & $\%(\mathrm{n})$ & $\%(\mathrm{n})$ & Row \% (n) \\
\hline $\mathbf{1 8 - 2 4}$ & $6.5(997)$ & $4.1(1054)$ & $3.2(1573)$ & $2.2(1559)$ & $1.9(804)$ & $2.4(1280)$ & $2.8(7267)$ \\
\hline $\mathbf{2 5 - 3 4}$ & $25.5(3909)$ & $19.6(5021)$ & $14.5(7252)$ & $12.0(8709)$ & $10.9(4625)$ & $13.5(7190)$ & $14.2(36706)$ \\
\hline $\mathbf{3 5 - 5 4}$ & $33.3(5105)$ & $33.5(8605)$ & $34.8(17346)$ & $37.6(27166)$ & $34.6(14641)$ & $33.7(18007)$ & $35.1(90870)$ \\
\hline $\mathbf{5 5 - 7 4}$ & $23.7(3638)$ & $28.5(7326)$ & $33.4(16667)$ & $34.6(26331)$ & $43.5(18385)$ & $43.1(23015)$ & $36.8(95362)$ \\
\hline $\mathbf{7 5 - 8 9}$ & $11.1(1704)$ & $14.3(3675)$ & $14.2(7069)$ & $11.8(8518)$ & $9.1(3856)$ & $7.4(3950)$ & $11.1(28772)$ \\
\hline All & $5.9(15353)$ & $9.9(25681)$ & $19.3(49907)$ & $27.9(72283)$ & $16.3(42311)$ & $20.6(53442)$ & $100(258977)$ \\
\hline
\end{tabular}

Table 2 goes here 
Table 3. Comparison of Loyalty Card and County Household Characteristics.

\begin{tabular}{|c|c|c|}
\hline Annual HH ${ }^{1}$ Income $(\$)^{*}$ & $\begin{array}{c}\text { LC }^{2} \\
\%(\mathbf{n ~ H H})\end{array}$ & $\begin{array}{c}\operatorname{ACS}^{3}(2017)^{29} \\
\%(\mathbf{n ~ H H})\end{array}$ \\
\hline $0-14.9 \mathrm{~K}$ & $6.1(16233)$ & $12.3(37056)$ \\
\hline $15-49.9 \mathrm{~K}$ & 29.4 (77691) & 33.3 (100056) \\
\hline $50-74.9 \mathrm{~K}$ & 27.7 (73276) & $17.7(53308)$ \\
\hline $75-99.9$ & $16.2(42785)$ & $12.4(37354)$ \\
\hline$\geq 100 \mathrm{~K}$ & 20.5 (54074) & $24.2(72722)$ \\
\hline Total HH & $100(264059)$ & $100(300496)$ \\
\hline Age-Group (years) & $\%(\mathrm{n} \mathrm{HH})$ & $\%\left(\right.$ (n People) ${ }^{4}$ \\
\hline $18-24$ & $3.7(10246)$ & $13.4(79001)$ \\
\hline $25-34$ & $14.7(41048)$ & $17.6(103767)$ \\
\hline $35-54$ & 34.9 (97378) & $31.8(187328)$ \\
\hline $55-74$ & $36.0(100248)$ & $28.3(166797)$ \\
\hline $75-89$ & $11.0(30215)$ & $8.9(52183)$ \\
\hline Total & $100(279135)$ & $100(589076)$ \\
\hline
\end{tabular}

${ }^{1} \mathrm{HH}$ : Household. ${ }^{2}$ LC: Loyalty Card. ${ }^{3}$ ACS American Community Survey. ${ }^{4}$ ACS does not provide data on age of head of household. *No statistically significant difference based on a Chi-square test p-value $<0.0001$ for household income group comparison between LC and ACS.

265 Seasonal Trends (figures 1 and 2).

266 Models for seasonal variation fit the data well for all months except for December and January,

267 in which the model over- and under-fits the data, respectively. The seasonal trends are consistent

268 in all age-and income-groups. A steady increase in percent produce purchased is observed from

269 January each year reaching its peak in April through July and gradually descending until 
270 December. The differences between these seasonal peaks and valleys are between 2\% and $3 \%$

271 produce purchased in all age and income groups. In the youngest age group (18-24 years old) the

272 peak percent produce purchased by households is below the overall mean (17\%) until the spring

273 of 2018 (figure 1). In the other age groups, the peak percent produce purchased by households

274 are above the mean for all households (17\%) in the spring, particularly in the 75-89-year-old

275 group. In the three lowest income groups, percent produce purchased are below the mean for all

276 households regardless of season (figure 2). Households whose income is $\geq 100 \mathrm{k}$ have a percent

277 produce purchased always above the mean regardless of the season.

278 Percent Produce Purchased at Baseline (Supplemental Table 4)

279 The baseline percent produce purchased is the expected percent produce purchased by

280 households as of January 1, 2016 (Supplemental Table 4). The youngest and oldest age groups

281 purchased the smallest and largest percent of produce (13.5\%, 95\% CI 13.1-13.9; and 16.8\%,

$28295 \%$ CI 16.6-16.9, respectively) (main effect of age group), although the trend is not consistently

283 upward by age group. Conversely, the percent produce purchased is larger as household income

284 increases, $13.9 \%$ (95\% CI 13.6-14.1) in the lowest and 17.1\% (95\% CI: 17.1-17.2) is the highest

285 household income (main effect of income group). When examining the joint contribution of age

286 and income groups to the percent produce purchased (interaction of age and income groups),

287 among households in age groups between 35 and 89, the higher the household income the larger

288 the percent produce purchased. In the youngest age groups, the contribution of income to

289 percent produce purchased does not have a consistent trend, particularly among the 18-24 year-

290 old households in which the proportion of produce purchased by income group is the most

291 varied. Within each household income group, although the oldest households always purchased

292 proportionally more produce than the youngest, the effect of age on percent produce purchased 
293 does not have a monotonic trend upward. In households at each income level, those in the 25-34

294 year old age group purchased a larger percentage of their groceries as produce than the

295 immediately younger (18-24) and immediately older (35-54) households. The largest difference

296 between the highest and lowest income groups in percent produce purchased is observed among

297 the 55-74 and 75-89 year old households (4.1\% and 5.2\%, respectively).

298 Linear Trends (Figure 3 and Supplemental Table 4)

299 Over the 33 months of data, there is an upward average linear change in percent produce

300 purchased per year of varied degrees. The youngest households increased their annual produce

301 purchased by $0.89 \%$ (95\% CI $0.74-1.04$ ) with a steady flattening of the trend in the subsequent

302 age groups down to the oldest households in which no change over time was observed $(0.03 \%$;

$30395 \%$ CI $-0.02,0.08$ ) (table 4 suppl, main effect by age). Although the income groups experienced

304 an annual increase in percent produce purchased, the rate of change was relatively similar across

305 income groups, with an annual increase in produce purchased of $0.41 \%$ (95\% CI $0.31-0.51)$ in

306 the lowest income group to $0.29 \%$ (95\% CI 0.31-0.51) in the highest one (table 4, main effect by

307 income). The joint contribution of age and income groups to annual average linear trend in

308 percent produce purchased is steepest among the 18-24 year old households at each income level

309 with more than or close to $1 \%$ a year up to the $50 \mathrm{~K}-74 \mathrm{~K}$ income group while the rate of annual

310 increase slows down at higher income groups although still higher than all other age-income

311 combinations. All other age-income combinations have average annual increase not exceeding

$3120.5 \%$. Of note, the oldest households (75-89 years-old) have almost no change in the average

313 annual percent produce purchased at all income levels 


\section{DISCUSSION}

316 We collaborated with a regional grocery store chain to explore the use of household food

317 purchasing data from a loyalty card dataset to examine long-term population trends in food

318 purchases. In this study, we described seasonal and linear trends in household fresh produce

319 purchasing as a proportion of total food purchases by age of head of households and household

320 income. We found clear seasonal trends over the 33 months of data in all age and income

321 groups. Superimposed to seasonal variations, we observed upward annual linear trends in

322 percent produce purchased over time in most households. The influence of household income

323 and age of head of household was more pronounced in the overall magnitude of produce

324 purchasing (baseline percent produce purchase as of January 2016) while change overtime

325 seemed to be more a function of age rather than income. Older households and households with

326 the largest income purchased a larger proportion of produce at baseline than younger and lower

327 income households in almost all combinations but the effect of income was particularly

328 pronounced in the two oldest household groups. The annual rate of change, however, was

329 especially fast in the youngest households (18-25 years-old) at all levels of household income.

330 Out of all food purchases, these young households are increasing the share of fresh produce

331 purchased by around 1\% per year while the oldest households (75-89 years-old) had an almost

332 flat annual rate of change in produce purchasing overtime regardless of household income.

334 The observed seasonal trends are as expected, a peak in the harvest months with valleys in 335 between (32). The seasonal peaks observed are parallel to the increase in variety and volume of 336 fruits and vegetables grown by farmers in the region who sell produce to the local groceries 337 stores (33). To our knowledge, no previous study described the joint effects of age of head of 
338 household and household income on linear trends in produce purchases in relation to all

339 household food purchases over almost three years of continuously collected data. Studies

340 present averaged data over time and show substantial methodological heterogeneity. Produce

341 purchases have been operationalized as dollars spent as a percentage of total household food

342 expenditures (34-37), per capita expenditures $(34,36)$, percent of purchased energy from

343 produce,(38) and per capita purchased servings per 1000 purchased kilocalories (39). Data on

344 purchases were collected from participants' receipts of purchases in all food outlets (grocery

345 stores, convenient stores, restaurants, markets, etc.) for 2-4weeks (35)', self-scanned purchases in

346 all food outlets for one year $(37,38)$ and participants' diary of all food expenses for 2 weeks

347 (34). Despite these differences, their findings are consistent with ours in that household income

348 consistently seems to drive produce purchasing. The wealthier the household the larger the share

349 of produce purchased $(34,35,40)$. Income was not related to produce purchases in only one

350 study (39) although the narrow range of household incomes in the sample may explain this

351 finding. In studies that adjusted for race, marital status (35) and educational attainment $(34,35)$,

352 the effect of income did not hold probably due to the high correlation among some of these

353 variables. Also consistent with previous evidence is the finding that the youngest households

354 (18-24 years old) purchase less produce than older ones but still the share of produce purchases

355 increases with household income (37). The 18-24 year old household's purchasing behavior may

356 reflect the transitional characteristics of this age group. People in this age group are more likely

357 to be living alone for the first time at college or working lower paying jobs or both and juggling

358 a young family; thus, favoring convenience (purchasing prepared or easy to make foods) over

359 fresh produce $(37,41)$. Another characteristic of younger shoppers is that they are value driven

360 and tend to prioritize organic foods and pay attention to their origin and to whether food is grown 
361 sustainably, characteristics that are mostly found at natural food sources, farmers markets, and 362 limited assortment stores $(42,43)$. The later may explain why younger households with high 363 incomes in our grocery store sample have a smaller percent produce purchased than older 364 households with the same income. Lower income households tend to favor calorically dense 365 foods to obtain more energy for dollar spent (44). Regional data on barriers to buying healthy 366 food support our interpretation. A little over $50 \%$ of area residents with income under $\$ 25 \mathrm{~K}$ 367 report cost as the most important barrier compared to $20 \%$ with an income over $\$ 75,000$. A 368 higher proportion of area residents aged 18-24 years old, relative to those aged 64 years and 369 older, reported cost (50\% vs. $18 \%$ ) and limited time to shop and prepare meals (30\% vs. 5\%) as 370 barriers to purchasing healthier foods (33).

372 The current study brings to light the effect of household age and income on long-term 373 longitudinal trends in produce purchasing behavior. We found that the rate of change over time 374 seems more a function of age rather than income. The fastest rate of growth among the youngest 375 households (18-25 year-olds) across income levels seems to indicate households' decisions to 376 purchase produce among this age group are influenced by factors other than income (e.g.; 377 adaptations over time, more education over the 33 months period). We do not have data to 378 evaluate whether this upward trend is the cross-sectional effect of age or a cohort effect. If the 379 latter, the findings among 18-24 year-old households highlights a healthy trend of increased fresh 380 produce purchases in the future. At an average rate of $1 \%$ increase per year in the proportion of 381 fresh produce purchased out of all other food products, in 10 years the share would increase by $38210 \%$ of all food purchases. Assuming that household produce purchases represent produce 383 availability in homes to consume, the upward trend in household produce purchases suggests a 
384 trend towards a healthier pattern in long term food consumption at the population level that may

385 contribute to a lesser chronic disease burden as the 18-24 year-old head of household cohort

386 ages. In all other age and income groups, the upward change is similar and relatively slow

387 especially in the 75-89 year-old household. The oldest households do not change their

388 purchasing behavior over time and income does not factor in, perhaps reflecting a generalized

389 resistance to change among older adults (45).

390

391 Contrary to the previous literature (34-38), our food purchase data were obtained from a single

392 grocery store chain in the county, thus missing purchases from other food outlets. It is difficult to

393 predict the effect these missing food sources has on our estimates, although we do not expect it

394 to be substantial given the store's large contribution to total dollar food expenditure in the county

395 and the broad representation of the county's total households (88\%) by loyalty card household

396 members. We expect, however, that the peaks in the harvest months observed might be

397 underestimated because produce bought at farmers markets or through community supported

398 agriculture shares are not included. Also contrary to large consumer panel studies with a

399 representative sample of the entire population $(34,37,38,41)$, our data are representative of our

400 county's population albeit with a smaller representation of lower income households. We are

401 unable to compare the food purchasing behaviors of the lower income households in our dataset

402 to the behaviors of lower income households in the county without loyalty cards. A meaningful

403 methodological advantage of the grocery store dataset is the absence of reporting errors. Datasets

404 obtaining purchase information from food receipts or scanners provided by study participants are

405 prone to random omissions or social desirability bias. In addition, the grocery store dataset has 
406 all household food purchases continuously collected for 33 months; thus, capturing usual long 407 term shopping behaviors.

409 CONCLUSIONS

410 Our study demonstrates the feasibility of a collaboration between researchers and a food retailer

411 to use loyalty card data for public health nutrition purposes. Since household food purchases are

412 in the intermediate pathway between the community food environment and household food

413 availability for consumption, household food purchases from grocery store databases have the

414 potential to be a more unbiased and representative estimate of long-term population dietary

415 patterns and be more sensitive to programs and policies than periodic surveys of self-reported

416 dietary intake. In larger markets, collaboration with all major food outlets would be necessary to

417 assess population purchasing trends. Household purchasing data from grocery store databases

418 offer many possibilities for public health nutrition research. For example, purchasing trends of

419 all other food groups may be examined to estimate the overall quality of foods available for

420 consumption within households, proportion of food dollars allocated to each food group,

421 differences by additional demographic characteristics, the effect of price fluctuations in foods

422 purchases, etc. Through the application of data science methods, grocery store foods, including

423 ready-to-eat and unprepared, can be linked with USDA nutrient composition databases for a

424 variety of uses related to better understanding the linkage between foods available for

425 consumption and the health status of a population. Understanding the food available within

426 households for consumption allows public health advocates to emphasize and promote the

427 purchasing of foods containing critical nutrients for specific stages along the life course such as

428 promoting the purchase of foods rich in lutein and zeaxanthin for the secondary prevention of 
429 age-related macular degeneration or rich in folate among women of reproductive age for the 430 primary prevention of birth defects.

432 LIST OF ABBREVIATIONS

433 DRNCD: Diet-related non-communicable diseases; US: United States of America; DALYs:

434 Disability-Adjusted Life-Years; ACS: American Community Survey.

436 SUPPLEMENTAL INFORMATION

437 Additional file 1. Table 1. STROBE-nut: An extension of the STROBE statement for nutritional 438 epidemiology

439 Additional file 2. Supplemental Table 4. Baseline ${ }^{1}$ and Rate of Change ${ }^{2}$ in Percent Produce 440 Purchased by Age and Income Groups.

442 ETHICS APPROVAL AND CONSENT TO PARTICIPATE

443 The University of Rochester Research Subjects Review Board approved all study procedures and 444 granted a waiver of consent.

445 CONSENT FOR PUBLICATION

446 Not applicable

447

448 AVAILABILITY OF DATA AND MATERIALS 
449 The data analyzed in the current study are not publicly available because these data are

450 proprietary. Data are however available from the authors upon reasonable request and with

451 permission of the grocery store leadership.

452

453 COMPETING INTERESTS

454 Mr. S. Prevost holds a managerial position in the grocery store company. All other authors declare 455 no competing interests.

456

457 FUNDING

458 The study was funded by the University of Rochester, Department of Public Health Sciences

459 Pilot Award and by the University of Rochester Flaum Eye Institute Department of

460 Ophthalmology Laboratory Funding (RSR). The funding sources had no role in the design of the

461 study, analysis, interpretation of results and writing the manuscript.

462

463 AUTHOR’ S CONTRIBUTIONS

464 IDF: conceptualization, methodology, data interpretation, writing original draft. BAJ: statistical

465 analyses methods, interpretation of results, writing, reviewing and editing manuscript. NW

466 conceptualization, food data management, interpretation of results, writing, reviewing and

467 editing manuscript. AK: food data management, interpretation of results, reviewing and editing

468 manuscript. JJ: methodology, data management and analysis, interpretation of results, reviewing

469 manuscript. SP: providing the data, interpretation of results, reviewing. JL: conceptualization,

470 reviewing manuscript. RSR: conceptualization, methodology, data interpretation, reviewing and

471 editing manuscript. Finally, all authors approved the manuscript. 


\section{ACKNOWLEDGEMENTS}

473 We thank the regional grocery store chain for its willingness to share the loyalty card database

$474 \quad$ with the research team.

475 The views expressed in this manuscript are the authors'only and are not necessarily shared by the 476 regional grocery store that has provided the data.

477

478

479

480

481

482

483

484

485

486

487

488

489

490 


\section{REFERENCES}

492

493

494

495

496

497

498

499

500

501

502

503

504

505

506

507

508

509

510

511

512

513

514

515

516

517

518

519

520

521

522

523

524

525

526

527

528

529

530

531

532

533

534

535

1. Global Burden of Disease 2017 Diet Collaborators. Health effects of dietary risks in 195 countries, 1990-2017: a systematic analysis for the Global Burden of Disease Study 2017. Lancet. 2019;393(10184):1958-72.

2. Mokdad AH, Ballestros K, Echko M, Glenn S, Olsen HE, Mullany E, et al. The State of US Health, 1990-2016: Burden of Diseases, Injuries, and Risk Factors Among US States. JAMA. 2018;319(14):1444-72.

3. Global Burden of Disease 2019 Risk Factors Collaborators. Global burden of 87 risk factors in 204 countries and territories, 1990-2019: a systematic analysis for the Global Burden of Disease Study 2019. Lancet. 2020;396(10258):1223-49.

4. Dao MC, Subar AF, Warthon-Medina M, Cade JE, Burrows T, Golley RK, et al. Dietary assessment toolkits: an overview. Public Health Nutr. 2019;22(3):404-18.

5. National Cancer Institute. Epidemiology and Cancer Research Program. Dietary Assessment Primer. [Available from: https://dietassessmentprimer.cancer.gov/learn/season.html.

6. Brennan L. Moving toward Objective Biomarkers of Dietary Intake. J Nutr. 2018;148(6):821-2.

7. Prentice RL. Dietary Assessment and Opportunities to Enhance Nutritional Epidemiology Evidence. Ann Intern Med. 2020;172(5):354-5.

8. Pfeiffer CM, Lacher DA, Schleicher RL, Johnson CL, Yetley EA. Challenges and Lessons Learned in Generating and Interpreting NHANES Nutritional Biomarker Data. Adv Nutr. 2017;8(2):290-307.

9. Economic Research Service (ERS), U.S. Department of Agriculture (USDA). 2012-2013 National Household Food Acquisition and Purchase Survey (FoodAPS) [updated August 20, 2019. Available from: https://www.ers.usda.gov/foodaps.

10. Bandy L, Adhikari V, Jebb S, Rayner M. The use of commercial food purchase data for public health nutrition research: A systematic review. PLoS One. 2019;14(1):e0210192.

11. National Cancer Institute. The Healthy Eating Index - What is the Food Stream? https://epi.grants.cancer.gov/hei/uses.html\#stream. Updated July 24, 2020. Accessed August 10, 2020

12. Appelhans BM, French SA, Tangney CC, Powell LM, Wang Y. To what extent do food purchases reflect shoppers' diet quality and nutrient intake? Int J Behav Nutr Phys Act. 2017;14(1):46.

13. Volpe R, Okrent A. Assessing the Healthfulness of Consumers' Grocery Purchases. USDA, Economic Research Service 2012, EIB-102. Available online: https://ageconsearch.umn.edu/record/262129/ (accessed on June 20, 2021).

14. Eyles $\mathrm{H}$, Jiang $\mathrm{Y}, \mathrm{Ni}$ Mhurchu $\mathrm{C}$. Use of household supermarket sales data to estimate nutrient intakes: a comparison with repeat 24-hour dietary recalls. J Am Diet Assoc. 2010;110(1):106-10.

15. Ransley JK, Donnelly JK, Khara TN, Botham H, Arnot H, Greenwood DC, et al. The use of supermarket till receipts to determine the fat and energy intake in a UK population. Public Health Nutr. 2001;4(6):1279-86.

16. Hecht A, Moran A, Snyder E, Lot tM, Arm K, Story M, et al. National Research Agenda to Support Healthy Eating through Retail Strategies. Durham, NC: Healthy Eating Research. Available at http://healthyeatingresearch.org. 2020.

17. USDHH and USDA. 2015-2020 Dietary Guidelines for Americans. 8th edition. 2015 [Available from: Available at http://health.gov/dietaryguidelines/2015/guidelines/.

18. Aune D, Giovannucci E, Boffetta P, Fadnes LT, Keum N, Norat T, et al. Fruit and vegetable intake and the risk of cardiovascular disease, total cancer and all-cause mortality-a systematic review and dose-response meta-analysis of prospective studies. Int J Epidemiol. 2017;46(3):1029-56. 
19. Martinez-Gonzalez MA, de la Fuente-Arrillaga C, Lopez-Del-Burgo C, Vazquez-Ruiz Z, Benito S, Ruiz-Canela M. Low consumption of fruit and vegetables and risk of chronic disease: a review of the epidemiological evidence and temporal trends among Spanish graduates. Public Health Nutr. 2011;14(12A):2309-15.

20. Veronese N, Solmi M, Caruso MG, Giannelli G, Osella AR, Evangelou E, et al. Dietary fiber and health outcomes: an umbrella review of systematic reviews and meta-analyses. Am J Clin Nutr. 2018;107(3):436-44.

21. Partula V, Deschasaux M, Druesne-Pecollo N, Latino-Martel P, Desmetz E, Chazelas E, et al. Associations between consumption of dietary fibers and the risk of cardiovascular diseases, cancers, type 2 diabetes, and mortality in the prospective NutriNet-Sante cohort. Am J Clin Nutr. 2020.

22. Cho E, Seddon JM, Rosner B, Willett WC, Hankinson SE. Prospective study of intake of fruits, vegetables, vitamins, and carotenoids and risk of age-related maculopathy. Arch Ophthalmol. 2004;122(6):883-92.

23. Wang X, Ouyang Y, Liu J, Zhu M, Zhao G, Bao W, et al. Fruit and vegetable consumption and mortality from all causes, cardiovascular disease, and cancer: systematic review and doseresponse meta-analysis of prospective cohort studies. BMJ. 2014;349:g4490.

24. Bowman SA CJ, Friday JE, Schroeder N, Shimizu M, LaComb RP, Moshfegh AJ. . Food Patterns Equivalents Intakes by Americans: What We Eat in America, NHANES 2003-2004 and 20152016. . Food Surveys Research Group Dietary Data Brief No 20. 2018.

25. Lee-Kwan SH ML, Blanck HM, Harris DM, Galuska D. Disparities in State-Specific Adult Fruit and Vegetable Consumption-United States, 2015. Morbidity and Mortality Weekly Report. 2017;66:1241-7.

26. Dietary Guidelines Advisory Committee. 2020. Scientific Report of the 2020 Dietary Guidelines Advisory Committee: Advisory Report to the Secretary of Agriculture and the Secretary of Health and Human Services. U.S. Department of Agriculture, Agricultural Research Service, Washington, DC.

27. Lachat C, Hawwash D, Ocké MC, Berg C, Forsum E, Hörnell A, et al. Strengthening the Reporting of Observational Studies in Epidemiology - nutritional epidemiology (STROBE-nut): An extension of the STROBE statement. Nutr Bull. 2016;41(3):240-51.

28. Granic A, Mendonca N, Hill TR, Jagger C, Stevenson EJ, Mathers JC, et al. Nutrition in the Very Old. Nutrients. 2018;10(3).

29. U.S. Census Bureau. American Community Survey. Selected Economic Characteristics. https://data.census.gov/cedsci/table?d=ACS\%205Year\%20Estimates\%20Data\%20Profiles\&table=DP05\&tid=ACSDP5Y2017.DP03\&g=0400000US36 0500000US36055\&vintage $=2017.2017$.

30. Liang KY, Zeger SL. Longitudinal Data-Analysis Using Generalized Linear-Models. Biometrika. 1986;73(1):13-22.

31. Zeger SL, Liang KY. Longitudinal data analysis for discrete and continuous outcomes. Biometrics. 1986;42(1):121-30.

32. Valpiani N, Wilde $\mathrm{P}$, Rogers B, Stewart $\mathrm{H}$. Patterns of fruit and vegetable availability and price competitiveness across four seasons are different in local food outlets and supermarkets. Public Health Nutr. 2015;18(15):2846-54.

33. Penisse M. Food and Health Connection. Final Report. Common Ground Health.; 2019.

34. Blisard N SH, Jolliffe D. Low-Income Households Expenditures on Fruits and Vegetables. United States Department of Agriculture. Agricultural Economic Report Number 833. 2004.

35. French SA, Tangney CC, Crane MM, Wang Y, Appelhans BM. Nutrition quality of food purchases varies by household income: the SHoPPER study. BMC Public Health. 2019;19(1):231. 
584 36. French SA, Wall M, Mitchell NR. Household income differences in food sources and food items $585 \quad$ purchased. Int J Behav Nutr Phys Act. 2010;7:77.

586 37. Kuhns A, Saksena M. Food Purchase Decisions of Millennial Households Compared to Other $587 \quad$ Generations, ElB-186, U.S. Department of Agriculture, Economic Research Service. 2017.

588 38. Pechey R, Monsivais P. Supermarket Choice, Shopping Behavior, Socioeconomic Status, and 589 Food Purchases. Am J Prev Med. 2015;49(6):868-77.

590 39. Rankin J, Winnet R, Anderson E. Food purchase patterns at the supermarket and their 591 relationship to family characteristics. Journal of Nutrition Education. 1998;30:81-8.

592 40. Pechey R, Monsivais P, Ng YL, Marteau TM. Why don't poor men eat fruit? Socioeconomic 593 differences in motivations for fruit consumption. Appetite. 2015;84:271-9.

594 41. Cook R. Tracking demographics and US fruit and vegetable consumption patterns. Department of Agricultural and Resource Economics. University of California, Davis. 2011.

42. Mintel Report. Perimeter of the Store. Published by Mintel Group Ltd. US, September 2019.

43. Fernandez C. Supermarkets and Grocery Stores in the US. US Industry (NAICS) Report 44511.

IBISWorld Inc. 2020.

44. Grummon AH, Taillie LS. Nutritional profile of Supplemental Nutrition Assistance Program household food and beverage purchases. Am J Clin Nutr. 2017;105(6):1433-42.

45. McCrae RR, Costa PT, Jr., Ostendorf F, Angleitner A, Hrebickova M, Avia MD, et al. Nature over nurture: temperament, personality, and life span development. J Pers Soc Psychol.

603 2000;78(1):173-86.

604 
Figure 1. Seasonal Trends in Percent Household Produce Purchased by Age Group (January 2016-October 2018). 

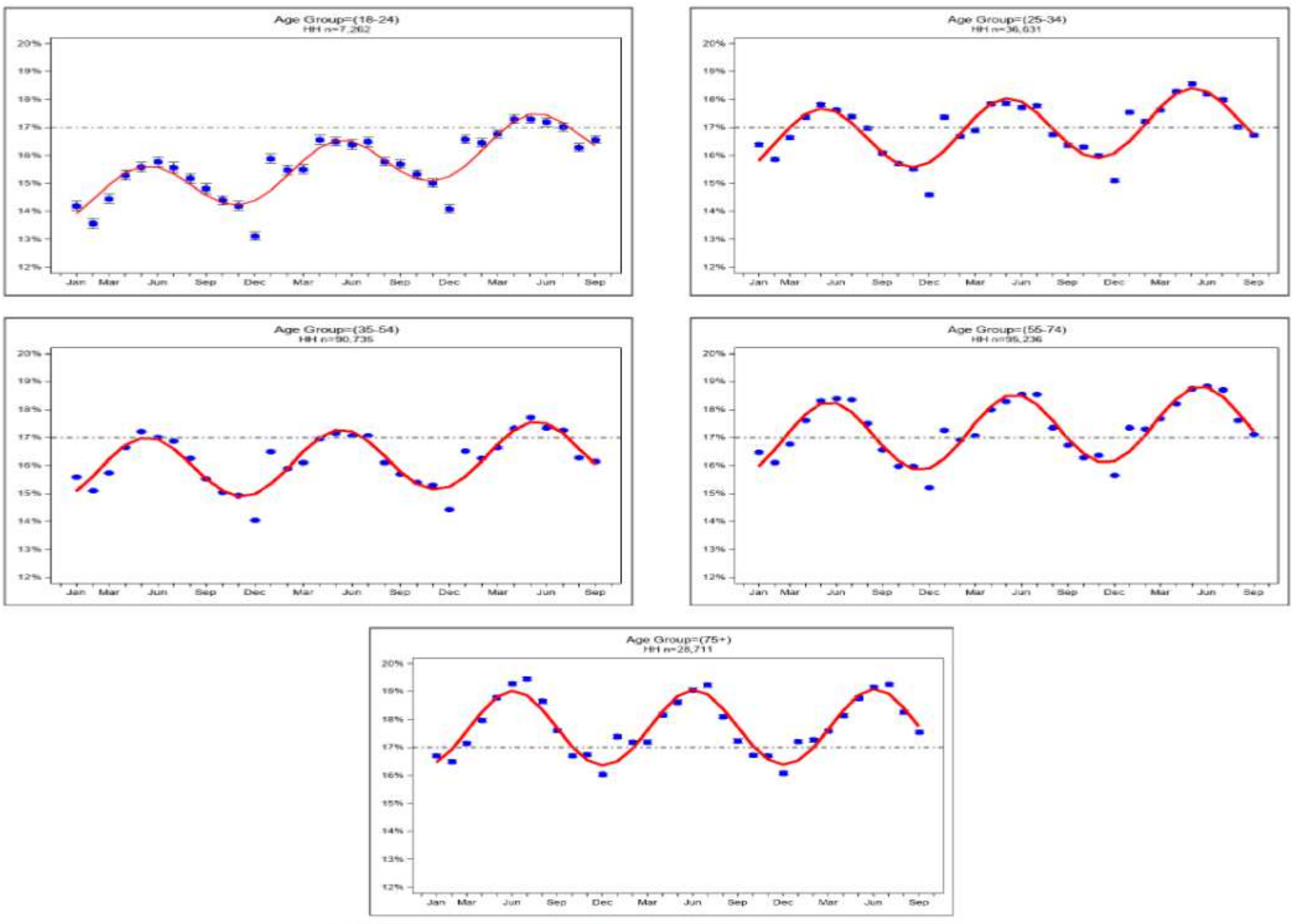

- - Observed Predicted Value - - Overall Avg 
Figure 2. Seasonal Trends in Percent Household Produce Purchased by Income Group (January 2016-October 2018). 

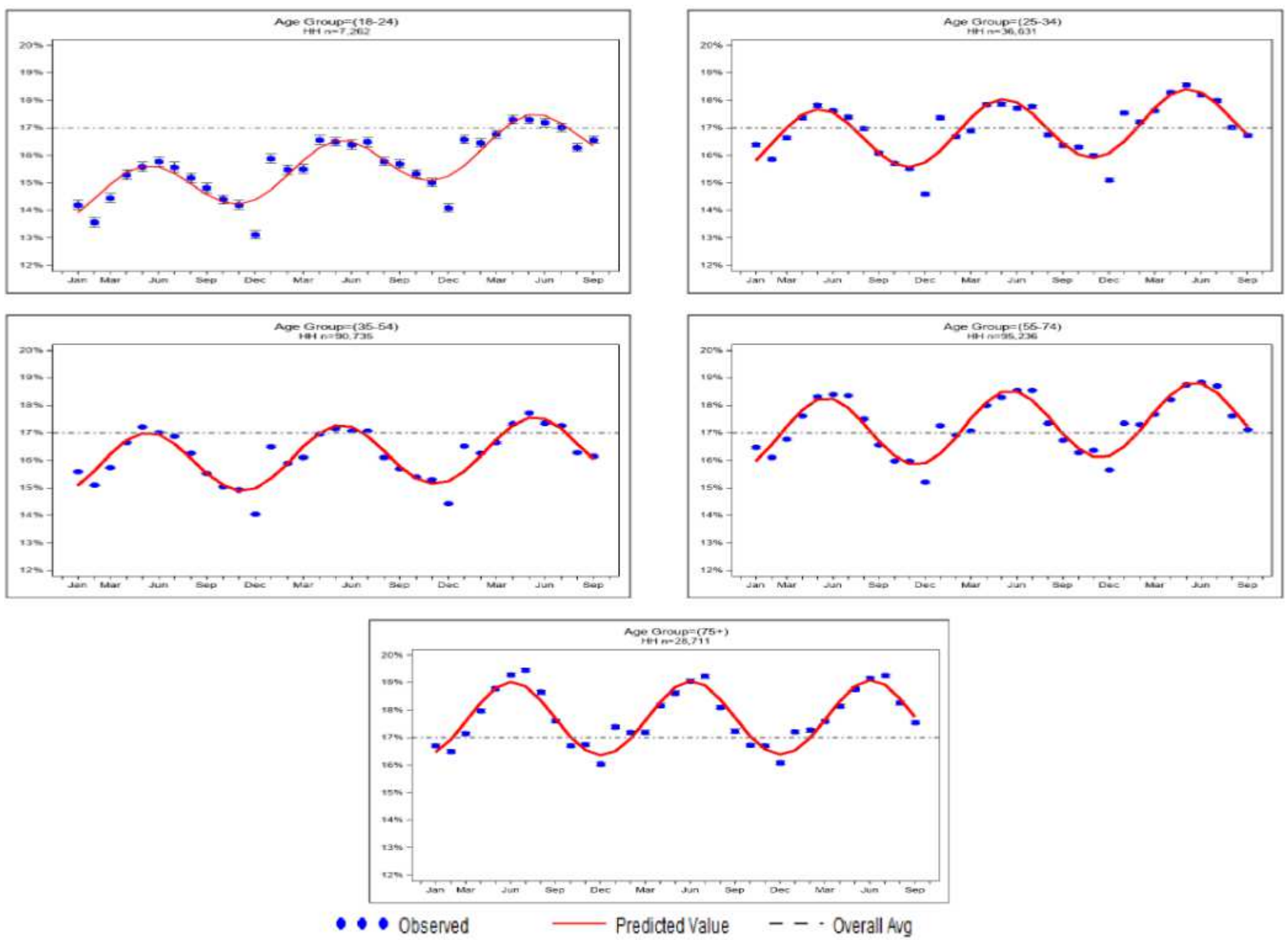
Figure 3. Annual Rate of Change in Household Produce Purchased by Income and Age Groups 


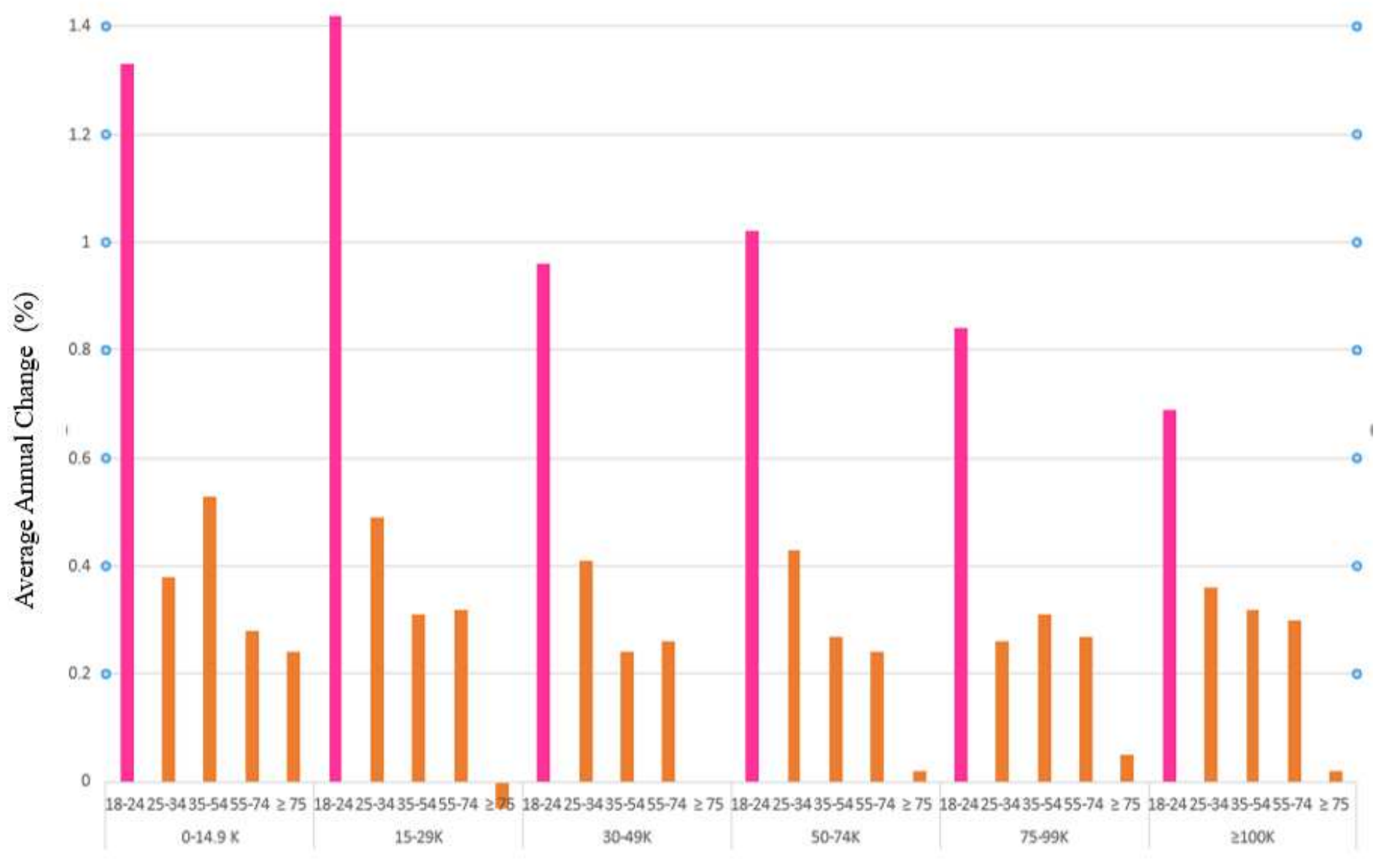

$0.2 \circ$

Household Income Group by Age Group of Head of Household 
Table 2. Characteristics of Loyalty Card Households by Age and Family Characteristics.

\begin{tabular}{|c|c|c|c|c|c|c|c|c|c|c|}
\hline & \multicolumn{3}{|c|}{ Family } & \multicolumn{7}{|c|}{ Household Size } \\
\hline $\begin{array}{c}\text { Head of } \\
\text { HH}^{1} \text { Age } \\
\text { (years) }\end{array}$ & $\begin{array}{c}\text { No } \\
\%(n)\end{array}$ & $\begin{array}{c}\text { Yes } \\
\%(\mathrm{n})\end{array}$ & $\begin{array}{c}\text { All } \\
\%(\mathrm{n})\end{array}$ & $\begin{array}{c}1 \\
\%(\mathrm{n})\end{array}$ & $\begin{array}{c}2 \\
\%(\mathrm{n})\end{array}$ & $\begin{array}{c}3 \\
\%(\mathrm{n})\end{array}$ & $\begin{array}{c}4 \\
\%(\mathrm{n})\end{array}$ & $\begin{array}{c}5 \\
\%(\mathrm{n})\end{array}$ & $\begin{array}{c}>6 \\
\%(\mathrm{n})\end{array}$ & $\begin{array}{c}\text { All } \\
\%(\mathrm{n})\end{array}$ \\
\hline 18-24 & $\begin{array}{c}1.8 \\
(2258)\end{array}$ & $\begin{array}{c}2.3 \\
(2787)\end{array}$ & $\begin{array}{c}2.1 \\
(5045)\end{array}$ & $\begin{array}{c}3.1 \\
(1400)\end{array}$ & $\begin{array}{c}1.2 \\
(691)\end{array}$ & $\begin{array}{c}1.4 \\
(814)\end{array}$ & $\begin{array}{c}2.0 \\
(751)\end{array}$ & $\begin{array}{c}2.4 \\
(566)\end{array}$ & $\begin{array}{c}3.8 \\
(823)\end{array}$ & $\begin{array}{c}2 \\
(5045)\end{array}$ \\
\hline $25-34$ & $\begin{array}{c}13.7 \\
(16937)\end{array}$ & $\begin{array}{c}12.4 \\
(14990)\end{array}$ & $\begin{array}{c}13.1 \\
(31927)\end{array}$ & $\begin{array}{c}22.4 \\
(10041)\end{array}$ & $\begin{array}{c}10.9 \\
(6300)\end{array}$ & $\begin{array}{c}10.3 \\
(6045)\end{array}$ & $\begin{array}{c}10.0 \\
(3817)\end{array}$ & $\begin{array}{c}11.5 \\
(2722)\end{array}$ & $\begin{array}{c}13.9 \\
(3002)\end{array}$ & $\begin{array}{c}13 \\
(31927)\end{array}$ \\
\hline $35-54$ & $\begin{array}{c}28.3 \\
(34919)\end{array}$ & $\begin{array}{c}42.5 \\
(51584)\end{array}$ & $\begin{array}{c}35.4 \\
(86503)\end{array}$ & $\begin{array}{c}36.8 \\
(16467)\end{array}$ & $\begin{array}{c}32.2 \\
(18653)\end{array}$ & $\begin{array}{c}35.5 \\
(20759)\end{array}$ & $\begin{array}{c}36.1 \\
(13745)\end{array}$ & $\begin{array}{c}37.6 \\
(8897)\end{array}$ & $\begin{array}{c}36.9 \\
(7982)\end{array}$ & $\begin{array}{c}35 \\
(86503)\end{array}$ \\
\hline $55-74$ & $\begin{array}{c}39.7 \\
(48919)\end{array}$ & $\begin{array}{c}36.1 \\
(43851)\end{array}$ & $\begin{array}{c}37.9 \\
(92770)\end{array}$ & $\begin{array}{c}29.5 \\
(13236)\end{array}$ & $\begin{array}{c}38.6 \\
(22369)\end{array}$ & $\begin{array}{c}39.4 \\
(23006)\end{array}$ & $\begin{array}{c}41.5 \\
(15785)\end{array}$ & $\begin{array}{c}41.1 \\
(9726)\end{array}$ & $\begin{array}{c}40.0 \\
(8648)\end{array}$ & $\begin{array}{c}38 \\
(92770)\end{array}$ \\
\hline $75-90$ & $\begin{array}{c}16.4 \\
(20154)\end{array}$ & $\begin{array}{c}6.7 \\
(8116)\end{array}$ & $\begin{array}{c}11.6 \\
(28270)\end{array}$ & $\begin{array}{c}8.2 \\
(3658)\end{array}$ & $\begin{array}{c}17.2 \\
(9943)\end{array}$ & $\begin{array}{c}13.4 \\
(7814)\end{array}$ & $\begin{array}{c}10.3 \\
(3927)\end{array}$ & $\begin{array}{c}7.5 \\
(1773)\end{array}$ & $\begin{array}{c}5.3 \\
(1155)\end{array}$ & $\begin{array}{c}12 \\
(28270)\end{array}$ \\
\hline All & $\begin{array}{c}50.4 \\
(123187)\end{array}$ & $\begin{array}{c}49.6 \\
(121328)\end{array}$ & $\begin{array}{c}100 \% \\
(244515)\end{array}$ & $\begin{array}{c}18.3 \\
(44802)\end{array}$ & $\begin{array}{c}23.7 \\
(57956)\end{array}$ & $\begin{array}{c}23.9 \\
(58438)\end{array}$ & $\begin{array}{c}15.6 \\
(38025)\end{array}$ & $\begin{array}{c}9.7 \\
(23684)\end{array}$ & $\begin{array}{c}8.8 \\
(21610)\end{array}$ & $\begin{array}{c}100 \% \\
(244515)\end{array}$ \\
\hline
\end{tabular}

${ }^{1} \mathrm{HH}$ : households. 


\section{Supplementary Files}

This is a list of supplementary files associated with this preprint. Click to download.

- Appendix1.Fernandezetal.STROBEnutchecklisttable.docx

- Appendix2.SupplementalTable4.docx 